\title{
Conscientização, tradição e desenvolvimento: a luta pela terra, o uso dos recursos naturais e conflitos em Unidades de Conservação no estado do Amazonas
}

Katiane Silva ${ }^{1}$

\section{Resumo}

Este artigo discute alguns aspectos do conflito protagonizado pelos moradores da comunidade Itaboca (extrativistas) e os indígenas Cocama da comunidade Santa União, situados na confluência entre duas Unidades de Conservação: a Reserva Extrativista Auati-Paraná e a Reserva de Desenvolvimento Sustentável Mamirauá, localizadas no estado do Amazonas. A atividade econômica que mais se destaca no local é o manejo comunitário do pescado, principalmente do pirarucu. De acordo com alguns moradores da região, essa atividade reacendeu antigas desavenças e causou novos conflitos entre moradores e instituições gestoras das reservas. Já por parte dos gestores, eles se empenham em conter os conflitos que surgiram a partir dessa nova modalidade de uso social dos recursos naturais. O modelo comunitáriocristão, cuja história remonta a década de sessenta, institucionaliza determinados papéis sociais na tentativa de efetivar o "desenvolvimento sustentável", no qual os seres humanos devem viver em harmonia e sempre sob a tutela externa de especialistas ambientais para legitimar as intervenções políticas e administrativas.

Palavras-chave: conflitos étnicos, produção de identidade, mediação de conflitos, Unidades de Conservação.

\footnotetext{
Abstract

This paper discusses some aspects of the conflict played by the extractivists Itaboca community residents and the indigenous Cocama of Santa União community, situated at the confluence of two protected areas: the Auati-Paraná Extractive Reserve and Mamirauá

${ }^{1}$ Doutora em Antropologia Social pelo PPGAS, Museu Nacional, Universidade Federal do Rio de Janeiro (UFRJ). A pesquisa foi realizada com bolsa de estudos da CAPES - Coordenação de Aperfeiçoamento de Pessoal de Nível Superior. E-mail:katiane.mars@gmail.com 
Sustainable Development Reserve, located in the state of Amazonas. The main economic activity is community management of fish, mainly pirarucu. According to some locals, this activity has reignited old disputes and caused new conflicts between residents and the reserves managing institutions. Managers strive to contain the conflicts arising from this new type of social use of natural resources. The Christian Community model, whose history dates back the sixties, institutionalizes certain social roles in an attempt to accomplish the "sustainable development", in which human beings should live in harmony and always under the foreign tutelage of environmental experts to legitimate political and administrative interventions.

Keywords: ethnic conflicts, production of identity, conflict mediation, protected areas.

Recebido em: Setembro, 2011

Aceito em: Setembro, 2015

Para citar este artigo:

SILVA, KATIANE; "Conscientização, tradição e desenvolvimento: a luta pela terra, o uso dos recursos naturais e conflitos em Unidades de Conservação no estado do Amazonas”. In: Revista Intratextos, 2014, vol 6, no1, p. 1-24. DOI: http://dx.doi.org/10.12957/intratextos.2014.2089 


\section{Introdução}

Este texto tem como objetivo esboçar alguns aspectos da emergência étnica e os conflitos potencializados a partir da criação de duas Unidades de Conservação (UC) de Uso Sustentável e a consequente racionalização do controle dos recursos naturais no Auati-Paraná, bacia do Rio Solimões, Amazonas. Esta região está situada na confluência entre a Reserva Extrativista (Resex) Auati-Paraná ${ }^{2}$ e a Reserva de Desenvolvimento Sustentável (RDS) Mamirauá ${ }^{3}$, localizadas nas regiões do Médio e do Alto Solimões.

As informações que serão apresentadas a seguir são fruto de parte da minha pesquisa de campo $^{4}$ e participação prévia no processo de estudos para a implantação do Plano de Manejo Participativo da Resex Auati-Paraná. Os dados consistem, basicamente, em três categorias: entrevistas, observação e pesquisa documental, dada a complexidade do campo. E durante as atividades da pesquisa foi possível perceber que diversas instâncias de gestão (seja estatal, religiosa, comunitária e étnica) estão interligadas, apesar de os gestores e representantes do Estado insistirem na distinção e instituição de categorias separadas.

A área conhecida como "complexo" de lagos do Buiuçu, composta por aproximadamente 24 lagos piscosos, é o cenário do surgimento de um movimento de reivindicação por terra indígena pelo grupo de Cocama, da família Arantes, que habitam a aldeia Santa União, ou comunidade indígena Santa União ${ }^{5}$. Com o auxílio de lideranças

2 Unidade de Conservação Federal de Uso Sustentável, criada a partir do Decreto de 7 de Agosto de 2001. É administrada pelo Instituto Chico Mendes de Conservação da Biodiversidade - ICMBio/MMA. Está localizada no Município de Fonte Boa/AM, possui aproximadamente uma área de 147.597.00 hectares ao longo do rio Auati-Paraná. As dezesseis comunidades que compõem a Resex Auati-Paraná estão distribuídas tanto à margem direita (dentro dos limites da RDS Mamirauá) quanto esquerda (dentro dos limites da Resex) do Rio AuatiParaná.

3 Criada por meio do decreto estadual 2.422 de 1996. Antes de ser instituída como reserva estadual, a RDS Mamirauá compreendia a Estação Ecológica do Lago Mamirauá, proposta pelo biólogo José Márcio Ayres e o fotógrafo Luiz Cláudio Marigo. A RDS Mamirauá foi a primeira unidade de conservação dessa categoria implantada no Brasil. É administrada em conjunto pelas seguintes instituições: Centro Estadual de Unidades de Conservação - CEUC/SDS; Sociedade Civil Mamirauá - SCM (co-gestora); e Instituto de Desenvolvimento Sustentável Mamirauá - IDSM/MCT (como braço executivo da SCM). Possui 1.124 .000 hectares, está localizada nos municípios de Uarini, Fonte Boa e Maraã, sendo também influenciada pelos municípios de Jutaí, Alvarães e Tefé, que é considerado o município mais importante da região do médio Solimões (IDSM, 2010).

${ }^{4}$ Realizada em quatro momentos, detalhados a seguir: em 2007, quando participei da viagem da equipe multidisciplinar do Instituto Nacional de Pesquisas da Amazônia (INPA); o segundo foi entre 2008 e 2009, durante minha pesquisa de mestrado no Programa de Pós-graduação em Antropologia Social da UFAM; o terceiro foi no início de 2010, quando fui professora assistente no curso de Licenciatura Intercultural Indígena da Universidade do Estado do Amazonas, em Tefé; e o quarto foi entre 2012 e 2013, durante a pesquisa de doutorado, pelo PPGAS/MN.

${ }^{5}$ A maneira como se constrói a noção de comunidade, analiticamente, está intimamente ligada com as relações de poder fundantes das estratégias do rearranjo territorial. A comunidade é vista como um "fenômeno" de modo 
indígenas dos municípios de Tefé e Jutaí, desde 2001, os Cocama vem solicitando junto à diretoria de assuntos fundiários da Fundação Nacional do Índio - FUNAI de Manaus a identificação da "Terra Indígena Aldeia Santa União". Esta iniciativa implicou na criação de uma situação de sobreposição de Terras Indígenas e Unidades de Conservação.

Este não é o primeiro caso de sobreposição na extensão territorial da RDS Mamirauá. Lá já existem quatro terras indígenas (TI): a TI Jaraqui, dos Kambeba; TI Porto Praia, dos Tikuna; TI Acapuri de Cima, dos Cocama; e parte da TI Uati-Paranã, dos Tikuna. Estas sobreposições são consideradas pelos gestores da RDS um problema para o desenvolvimento dos trabalhos do manejo pesqueiro, pois acreditam que as regras estabelecidas no Plano de Gestão não serão respeitadas (IDSM, 2010).

Em alguns casos, a presença indígena em UC's não é bem vida. No entanto, as opiniões de alguns mediadores estatais divergem: enquanto para alguns funcionários do ICMBio o "assunto indígena dentro da Reserva está morto e enterrado", outros reconhecem e acreditam que esta é uma manifestação legítima dos grupos que reivindicam o direito à terra $\mathrm{e}$ aos serviços de responsabilidade do Estado, como educação e saúde, além da possibilidade da utilização dos recursos naturais como principal fonte de renda.

Ao categorizar ligeiramente os conflitos de maneira que auxilie na descrição da questão tratada, é possível perceber sua ocorrência em várias instâncias: entre os moradores das reservas (usuários e beneficiários) e instituições mediadoras; entre moradores e invasores; entre moradores e empresários-posseiros; entre representantes do Estado; e entre os próprios moradores, que podem ser considerados comunitários ou indígenas. É justamente esta última categoria que vai nortear a discussão. O conflito aqui é protagonizado pelos moradores da comunidade Itaboca e pelos indígenas Cocama da aldeia Santa União, todos membros de uma mesma família: Arantes.

A comunidade Itaboca, apesar de também estar localizada dentro dos limites da RDS Mamirauá, é associada à Resex Auati-Paraná. Os Arantes que vivem em Itaboca não negam sua origem Cocama, mas se consideram "comunitários" ou "ribeirinhos". De acordo com Isaac Arantes, atualmente presidente da Associação Agroextrativista do Auati-Paraná organização das principais instituições que as conformam. A filiação das comunidades a uma Unidade de Conservação ou à Terra Indígena é geralmente uma consequência do contexto histórico e das negociações decorrentes da atuação do Estado e seus efeitos sociais. Utilizo este termo a partir da reflexão feita tanto pelos indígenas quanto pelos extrativistas, por se considerarem participantes de comunidades com uma história e ligação comum, e que se constitui a partir do seu fazer político. 
(AAPA), ele e os Arantes que vivem em Itaboca, acreditam que "para ser indígena" é necessário "algo mais", uma cultura específica que não se estabelece somente com a prática da pesca. Por isso, afirmam sua ascendência indígena, mas não se consideram como tal, pois já "estão civilizados".

No entanto, os argumentos dos Cocama sobre a sua condição indígena estão embasados na história da família, na prática e fluência da língua indígena e, principalmente, na atuação engajada no movimento indígena. De acordo com Joel, presidente da Associação dos Comunitários de Santa União (ACSU), para ser indígena hoje não bastam apenas os aspectos diacríticos considerados usuais, como pinturas corporais, mas é necessário um conhecimento sobre a legislação, uma inserção ativa na rede de relações estabelecidas em assembleias e reuniões promovidas pelo Movimento Indígena.

Para alguns gestores das UC's, os conflitos entre as comunidades são considerados um empecilho para o projeto de conservação, já que podem prejudicar o uso apropriado dos recursos naturais, de acordo com as normas de documentos específicos como Plano de Manejo ou Plano de Gestão das Unidades de Conservação ${ }^{6}$. Apesar de alguns mediadores do Estado considerarem a disputa pelo Buiuçu "uma briga de família”, será possível perceber que ele ultrapassa a questão étnica e a familiar. Esses eventos decorrem de uma história de violência e dominação, que caracterizou o processo de formação social e regional do município de Fonte Boa, assim como de muitos municípios do Estado do Amazonas, marcados pela relação de patronagem e pela disputa da hegemonia econômica e política do município.

\section{Organização social e conscientização: o ordenamento territorial e o projeto pedagógico da igreja católica}

A presença da igreja católica na região estudada é representada pela Congregação do Divino Espírito Santo. Os espiritanos, como são conhecidos popularmente, compõem uma congregação missionária, resultado da união de duas congregações. A primeira foi fundada pelo Pe. Cláudio Poullart no Domingo de Pentecostes de 1703, em Paris e a segunda pelo Pe. Francisco Libermann no ano de 1841. E em 1848, foi formada a Congregação do Espírito

\footnotetext{
${ }^{6}$ O Plano de Manejo Participativo, para a Resex, e o Plano de Gestão, para a RDS, são documentos técnicos que estabelecem o zoneamento e as normas administrativas das Unidades de Conservação, têm como principal função fazer cumprir os objetivos da Unidade e orientar a gestão da conservação.
} 
Santo e do Imaculado Coração de Maria.

Os primeiros espiritanos desembarcaram em Belém/PA, em 1885, para assumir a direção do Seminário Menor ${ }^{7}$. A partir de 1892, em resposta ao pedido do bispo de Manaus, assumiram uma missão no município de Tefé onde lideraram o trabalho de evangelização dos indígenas. Dentre esses missionários, destacou-se no campo da etnologia o padre Constant Tastevin, que interagia com os índios, coletava informações etnográficas, fazia um trabalho de conversão dos índios ao cristianismo e os ensinava os "costumes civilizados". Em seus escritos, Tastevin (2008) dá indícios de que além do caráter missionário do seu trabalho havia a disputa pelo território, tanto no campo político-administrativo quanto no campo do saber.

A estratégia de atuação das missões no Amazonas está diretamente relacionada com a formação de um etos civilizado, apoiado na pedagogia cristã de preparação para o trabalho e para a vida civilizada, representada pelo modelo urbano. A organização missionária tinha o objetivo de trabalhar em duas frentes: a organização e instalação dos prédios da missão no núcleo urbano ou nas aldeias; e a organização das constantes viagens para o interior dos municípios para a realização das desobrigas, ou seja, visitas aos moradores mais distantes, distribuídos ao longo dos rios e interior dos seringais e colônias para realizar batismo, comunhão, casamentos, evangelização e recenseamento da população (PIRES MENEZES, 2002).

Este modo de vida "selvagem" só poderia ser extinto a partir da modificação da estrutura social, tanto física quanto política. De acordo com os preceitos da igreja, era necessário não apenas agrupar as pessoas em comunidades, mas formá-las politicamente. E o processo de formação de lideranças comunitárias ficou a cargo do Movimento de Educação de Base (MEB) e da Prelazia de Tefé.

A ação pedagógica do MEB tinha como base textos sobre sindicalismo, cooperativismo, legislação, entre outros temas que interessavam a formação de pessoal qualificado para liderar os grupos. Além de auxiliar no reagrupamento da população local em comunidades. Outra estratégia do MEB foi a alfabetização da população por meio da Radio Educação Rural de Tefé, onde os educadores ministravam cursos e disseminavam informações importantes como os preços dos produtos que a população necessitava e a cotação de preços da borracha.

Esta organização social em comunidade apresentava um diferencial: apropriação do

${ }^{7}$ Fonte: http://www.espiritanosbrasil.org. 
discurso ambiental como um modo eficaz de combate aos madeireiros, proprietários de frigoríficos, regatões ou antigos "patrões" seringalistas. Essas apropriações também provocaram mudanças nos padrões de comportamento e concepção do espaço. Estabeleceram um arcabouço de normas, valores e ações que resultaram na criação de Reservas Extrativistas no Estado do Amazonas, nos municípios de Carauari, Juruá, Jutaí e Fonte Boa. Apesar de a categoria Reserva Extrativista carregar um registro de luta dos movimentos sociais num momento histórico muito particular, sua implementação passa, em seguida, por um processo de burocratização que, arbitrariamente, adiciona a ela o estigma do desenvolvimento sustentável.

No início da década de 90, por meio de assembleias promovidas pela paróquia de Fonte Boa, foram constituídos grupos de trabalho e estabelecidas parcerias com diversas instituições locais para a formação de pessoas para a organização de uma associação, a Associação Agro-extrativista do Auati-Paraná $\left(\mathrm{AAPA}^{8}\right)$, que impulsionou a criação da Resex Auati-Paraná.

Durante este período tanto Itaboca quanto Santa União participaram efetivamente apesar da relação pouco amistosa entre os parentes. Esta união caracterizou-se como um momento de negociação para a garantia da permanência das famílias naquele lugar, já que trata-se de uma área sob constante pressão de posseiros e grandes empresários do ramo pesqueiro.

A solução para as ameaças seria possível a partir da "conscientização" da população, conforme relatos de representantes da Igreja. Estava lançado um grande desafio: chamar, agrupar as pessoas e, posteriormente, fazê-las acreditarem em um projeto extrativista concreto. Além disso, o apoio do governo federal era algo considerado praticamente impossível, pois entre os comunitários havia principalmente o medo da submissão às leis externas de um governo ou vários governos que nunca estiveram presentes, a não ser no período eleitoral.

Para o êxito deste projeto seria necessário obedecer e cumprir os deveres estabelecidos e fixados nos estatutos legais, no caso a legislação ambiental, para o uso eficaz dos recursos naturais. E neste caso a força estaria fundada na obediência condicionada pelo medo e a pela esperança. O medo de ser expulso do lugar de origem, o medo de sofrer punição por infração

\footnotetext{
${ }^{8}$ Fundada em 01 de fevereiro de 1998 e tinha como objetivo principal a organização dos comunitários para a criação da Reserva Extrativista Auati-Paraná (ARANTES, 2006). 
às normas estabelecidas pelo Sistema Nacional de Unidades de Conservação ${ }^{9}$.

A experiência prévia com órgãos como o IBAMA ou o Instituto de Desenvolvimento Sustentável de Fonte Boa (IDS) ${ }^{10}$ indica controvérsias e atritos durante a fiscalização no período da despesca. Segundo relatos de comunitários, por diversas vezes os pescadores passaram por situações violentas durante as fiscalizações, foram submetidos à apreensões e até mesmo à violência física.

$\mathrm{Na}$ "engenharia" de mediação de conflitos, idealizada por os funcionários especializados das instituições gestoras, o domínio efetivo é apropriado no cotidiano administrativo por funcionários do Estado, responsáveis por executar ações rumo à burocratização crescente. No caso do Auati-Paraná, o monopólio da mediação pelos missionários espiritanos foi transferido gradativamente para as instituições gestoras estatais e não governamentais. Isto não significa que o trabalho missionário foi excluído do esquema de organização e tomada de decisão, mas representou um aspecto da luta pela dominação neste campo de disputas.

\section{Entre a tradição e o conflito: "hoje em dia é mais negócio ser indígena do que extrativista ou comunitário, porque a Funai tem mais poderes"}

Entre os anos de 2003 e 2005 os indígenas e os comunitários do Auati-Paraná enfrentaram dificuldades durante o período de despesca no complexo de lagos do Buiuçu. $\mathrm{O}$ motivo principal foi a coação do suposto proprietário da área, um empresário do ramo da comunicação no Amazonas, que obrigava os pescadores a pagarem um percentual da renda obtida com a produção. Segundo o secretário da AAPA, os comunitários foram obrigados a assinar um documento no qual acordavam em pagar $20 \%$ do valor obtido com a venda da produção.

Por meio de um representante, em 2005, o empresário firmou um contrato com as lideranças no qual a comunidade e a aldeia deveriam pagar um valor equivalente a metade de toda a produção em troca do uso dos lagos. Foi um contrato formalizado em juízo, o que

\footnotetext{
${ }^{9}$ Instituído por meio da Lei ${ }^{\circ} 9.985$ de 18 de julho de 2000.

${ }^{10}$ Autarquia municipal criada em 2003 no governo do prefeito Wilson Lisboa, agregando funções de secretaria de meio ambiente e de produção. Também atua em conjunto com o IBAMA na fiscalização da pesca tanto na RDS Mamirauá quanto na Resex Auati-Paraná.
} 
obrigou o IBAMA a acionar a Advocacia Geral da União para anular o documento.

A pesca do pirarucu no estado do Amazonas só é permitida através do sistema de manejo, monitorado todos os anos pelo IBAMA, que determina e libera a quantidade de peixe a ser retirado dos lagos. De junho a novembro a pesca é liberada em unidades de conservação de uso sustentável desde que todas as partes respeitem as regras estabelecidas, que geralmente são publicadas no documento chamado Plano de Manejo ou Plano de Gestão.

A RDS Mamirauá possui um Plano de Gestão, atualizado em 2010, e sua principal modificação foi uma maior abrangência do documento, em termos legais, na área total da reserva. A primeira versão, de 1996 e ainda denominada Plano de Manejo, dividia a extensão de um milhão de hectares da unidade em área focal e área subsidiária. O antigo Plano de Manejo priorizava suas atividades apenas a área focal (260.000 hectares), próxima ao município de Tefé, e a justificativa era a impossibilidade de abarcar toda a extensão por falta de pessoal ou de mecanismos legais para isso. Consequentemente, os 864.000 hectares da área subsidiária foram excluídos de uma atuação intensa.

As comunidades da Resex Auati-Paraná estão localizadas na antiga área subsidiária da RDS Mamirauá. E este fato provocou situações indesejadas para os gestores da RDS, já que os comunitários não seguiam legislação porque não havia conhecimento das regras e muito menos atividades de manejo na região. Em 2003, por meio de parcerias entre o Instituto de Desenvolvimento Sustentável de Fonte Boa e o IBAMA, o manejo do pirarucu foi implementado gradativamente. No entanto, como a Resex Auati-Paraná ainda não possui um Plano de Manejo seus gestores acreditam que isso é um impasse para a execução das normas.

O manejo comunitário, consiste no cumprimento de uma série de procedimentos, desde a participação dos comunitários em capacitações, discussões para implementação de regras de uso dos lagos, contagem dos estoques de peixes e, principalmente, a contenção dos conflitos, que são muito comuns. Geralmente, a cota de pesca anual é baseada no resultado da contagem de pirarucus, retirando-se $30 \%$ dos adultos, restando $70 \%$ para a reprodução (AMARAL, 2007). Durante os meses de dezembro a maio é proibida a captura do pirarucu. É o chamado período de defeso, no qual os pescadores recebem o seguro defeso ${ }^{11} \mathrm{e}$ complementam a renda com o trabalho na roça ou em pequenos comércios.

É a falta de clareza e o embate entre instituições e legislações que compõem o cenário

\footnotetext{
${ }^{11}$ Auxílio financeiro temporário concedido ao pescador profissional que exerça sua atividade de forma artesanal, que teve suas atividades paralisadas no período de defeso, no qual os peixes se reproduzem. 
no qual o caso do Buiuçu se desenrolou, tendo como consequência um agravamento nas desavenças entre os parentes de Itaboca e Santa União. Segundo o secretário da AAPA, os indígenas abandonaram o projeto extrativista em função da orientação dos funcionários da Funai de Tefé. Eles aconselharam os Cocama a deixarem a Resex porque "segundo a lei não pode haver indígenas em reservas extrativistas".

Isto demonstra a disputa na produção de categorias identitárias e os seus respectivos lugares no governo territorial e populacional. O estabelecimento da relação tutelar entre gestor e comunitário é uma interpretação superficial da legislação, na qual afirma-se que só pode haver índio em terra indígena, ou extrativista em unidade de conservação de uso sustentável. Aparentemente, a longa história de desentendimentos entre Itaboca e Santa União, como mencionado anteriormente, também está relacionada também com divergências religiosas. $\mathrm{Na}$ década de 70, parte da família migrou para o município de Jutaí com o intuito de se converterem à religião da Santa Cruz e seguirem os preceitos religiosos do Irmão José Francisco da Cruz.

Foi desse irmão José que surgiu essa religião. Ele ia pras comunidades e trazia aquelas cruzes pra implantar nas comunidades. Então foram-se embora os meus parentes, pegaram essa cruz e implantaram na comunidade deles. Eles queriam que nós acompanhasse eles. Só que a gente não aceitou e como a gente não aceitou eles começaram a ficar assim revoltados, não gostavam mais de ninguém, que a gente não ia acompanhar e era um bando de bicho. Que se a gente acompanhasse eles ia se salvar, aquela coisa. (Comunitário de Itaboca)

O irmão José Francisco da Cruz percorreu aldeias e povoados, desde o Peru, implantando e pregando devoção à cruz como uma estratégia de salvação do perigo iminente: o fim do mundo. Como observou Cardoso de Oliveira (1975), a ideia central deste movimento milenarista é a da salvação dos fiéis a partir da reunião em torno da Cruz com o objetivo de sobreviver a um cataclismo futuro.

Os maiores incentivadores do movimento foram os comerciantes ou patrões que perderam ou estavam perdendo influência política e econômica na região. Segundo Erthal (1998), sob a influência desta religião não havia questionamentos a respeito da situação dos indígenas, mas um reforço da relação de dependência e subordinação aos patrões, que 
exerciam liderança religiosa e econômica.

A interpretação desses eventos, tanto a adesão ao movimento da Santa Cruz, como a auto identificação indígena não pode ser pensada somente a partir de uma lógica instrumentalista. É preciso, como indica Oliveira Filho (1988), confrontar o movimento com outras manifestações e tentar verificar os padrões de diferenças e semelhanças levando em consideração as diversidades de contextos. Ao que parece, é justamente o caráter sobrenatural das desses movimentos que mobilizam as pessoas em torno de uma reposta para a mudança da condição social.

Lembrando ainda que esses movimentos não correspondem a estágios de aculturação, mas parecem possuir um caráter lógico e racional, que, no caso dos Tikuna, é pensada como estratégias para possível resistência face ao domínio dos seringalistas. Em algumas entrevistas é possível perceber a etnicidade constantemente relacionada à religião da Santa Cruz, no entanto não se pode reduzir esta questão ao estabelecimento de um determinado rótulo. É preciso compreender como este aspecto se localiza na relação com o Estado, a economia, as diversas ideologias nas quais essas relações foram construídas.

Uma outra questão que é constantemente debatida e gera desavenças entre os parentes é a utilização do lucro obtido com a venda da produção. Segundo o secretário da AAPA, a aldeia Santa União foi a que mais lucrou no ano de 2007 com a produção do manejo do pirarucu. Ao relatar este fato ele demonstrava indignação porque "esses índios recebiam o dinheiro e iam pra cidade gastar tudo com cachaça. Eles não fizeram nada pra melhorar a estrutura da comunidade, por exemplo, as casas continuam em condições precárias”.

E daí também surgem as diversas teorias sobre a produção de identidade indígena, até que ponto ser ou não ser índio é ou não vantajoso nesta situação. Essa questão não está fixada apenas no interesse ou em mudança de condição social, mas parece resgatar o debate sobre raça, dissimulado nas noções de identidade. Percebe-se a necessidade de se estabelecer um "índio puro", e sua relação com a invenção da tradição, como fundamental no jogo de legitimação social.

Para Epstein (1978), a formação da identidade étnica está em função de variáveis internas e externas que operam em um dado ambiente social. A identidade étnica não é dada, nem inata; o modo como é como ela é gerada é sempre um processo psicossocial. Ele afirma ainda que as categorias étnicas possuem sempre um aspecto dual: são objetivas porque dependem da afirmação exterior ou independente do ator social; e subjetivas, porque é a 
percepção que o ator possui de si.

Neste caso, o discurso de um líder indígena (do município de Tefé) que auxilia os membros da aldeia Santa União a reconhecerem sua identidade e seus direitos também nos remete a uma construção ideológica comunitária, no sentido weberiano, para um fim político. O que une os Cocama é a crença na origem comum, as comunidades do Peru, o habitus, a vivência cotidiana e o objetivo de conquistar um território pressionado por diversos atores sociais.

Eu conheço lá muito bem, eu nasci e me criei ali. Eu vivi lá uns 36 anos, lá no Auati-paraná. A Santa União era meu vizinho. Eu morava do outro lado, acima do Buiuçuzinho. A minha mulher é filha de lá do Itaboca. O pessoal é tudo parente, é tio, é primo. E eu conheço muito bem como foi essa versão aí.

Nos anos 50 eles sabiam que eram índios Cocama, mas tinham vergonha de se identificar, de se declarar. Porque se achavam menores do que todo mundo. Aí veio esse tempão todinho, e quando viram que eu tava na frente de coordenação de terras indígenas, aí eles vieram comigo e eu falei que o futuro se ganha assim: Eu sou Cambeba, meus pais também são Cambeba. Quando eu entrei no movimento indígena eu fui fazer uma pesquisa no Peru. Eu fui e depois que voltei fui me declarar. E depois eu fui lá no Peru, nas terras indígenas dos índios Cocama do Peru. Todos eles são peruanos.

Eu acho que o pessoal da Santa União não quer mais a Itaboca por lá porque houve muito conflito. Já brigaram, quebraram a cabeça de um, bateram em outro. Levaram até barco pra invadir. É por causa desses conflitos que santa união não aceita mais. O pessoal da Santa União e da Itaboca tudo é indígena. Só que é como eu falei, eles tinham vergonha de se identificar. E eu tenho certeza que lá no Peru é o tronco da onde eles vieram. (Liderança do movimento indígena do município de Tefé)

A proposta de Weber (1983) é muito clara ao destacar as condições básicas da "pertinência à raça" dos grupos comunitários: a origem comum e as afinidades sentidas subjetivamente. A primordialidade, o ponto de partida para o pertencimento ao grupo, é uma construção com uma finalidade política. Portanto, o ponto fundamental para o autor é a ação social e a posição destes atores no processo político, ou seja, a comunidade étnica é uma forma de organização social que parte da ação com interesses políticos. Assim, a concepção de ação política torna-se uma opção contrária aos estudos de aculturação e assimilação que tentam integrar ou adequar os grupos minoritários a uma sociedade abrangente.

É evidente em alguns relatos que raça, classe e cultura se inter-relacionam. E a 
naturalização da descendência reifica essa tradição, que é o principal requisito para permanência no lugar de origem. Ao mesmo tempo em que os Cocama são considerados, em determinados momentos, um grupo inferior, a emergência da identidade étnica é considerada uma espécie de resposta à condição subalterna imposta durante muitos anos.

Contudo, neste campo de disputas as diversas opiniões entram em choque, principalmente quando se trata da incorporação de uma atividade econômica que não condiz com a imagem ideal de índio e tradição:

Pra mim, essa coisa de terra indígena foi mais interesse de ganhar os lagos, isso aí tá na cara. Foi tudo interesse em adquirir uma propriedade, mas cultura mesmo, tradição eles não tem. Tradição é assim, vamos supor, o interesse era tão grande que dá pra notar assim que eles não tem cultura. Porque o índio, ele não vive só de pesca, tem que ter outra cultura. Eles sempre falam que eles não se deram bem com nós porque eles são índios e nós somos brancos. Eles chamam a gente de branco (risos). E nós somos do mesmo sangue, da mesma família.

Mas aí depois dessa briga toda é que começou a desavença. De lá a gente fez um acordo sobre o que podia pescar, quando e como. Mas uns queriam tirar mais outros menos. Aí eles viviam viajando de Jutaí até Tefé, entraram em contato com a UNITEFÉ e a UNI-TEFÉ disse vocês tem que se declarar como índio e rapidinho vocês tem esse lago, tira da mão dos proprietários e é de vocês.

Um deles foi um tio meu. Ele era o chefe da UNI-TEFÉ, eu não sei agora. Por isso que a Santa União se declarou indígena porque são da família dele, da nossa família, da mamãe. Diz que também a minha etnia é Cocama. (Vice-secretário da AAPA)

A busca por elementos que comprovem a tradicionalidade ou autenticidade da cultura é um aspecto fundamental da construção da etnicidade, "porque o índio, ele não vive só de pesca, ele tem que ter outra cultura". De acordo com os critérios classificatórios arbitrários, o índio tem que ter, no mínimo, uma raça (aqui relacionada à etnia), uma língua e uma religião diferentes da chamada sociedade envolvente. Os Cocama respondem aos critérios fenotípicos do que se entende por índio no imaginário oficial. Contudo, nesta configuração social, "ter cara de índio" não basta. Essa diferença que faz valer a indianidade não é tão evidente entre eles, já que seus parentes de Itaboca também "tem cara de índio", mas não são índios.

A existência da tutela, tanto em relação aos índios quanto aos comunitários, torna-se moeda de troca. É importante observar como as diversas construções ideológicas são 
concretizadas nos discursos e nas negociações dos atores sociais: "hoje em dia é mais negócio ser indígena do que extrativista ou comunitário, porque a Funai tem mais poderes”, afirmou o secretário da AAPA ao relatar sobre os diversos momentos em que foi abordados por seus companheiros de trabalho. Continuou: "se eu quisesse ser indígena eu poderia, já que eu sou Cambeba por parte de mãe e Cocama por parte de pai, mas eu me vejo como um comunitário".

Como afirma Banton (1977), a etnicidade, assim como a nacionalidade, é uma qualidade compartilhada. Ele trata a etnicidade como a qualidade de um grupo que nutre um sentimento de pertença, com a particularidade de que seus membros tem consciência de sua participação. A auto-consciência, no sentido de participar e saber porque está participando, é um dos pontos-chave desta discussão. Assim como o secretário da AAPA afirmou que poderia ser indígena se quisesse, Banton concorda que "ninguém é obrigado a ser membro da mesma minoria étnica ou religiosa de seus pais porque, se o indivíduo for determinado, pode romper com essa identidade e integrar-se com qualquer outro grupo" (p. 169).

\footnotetext{
A briga mais forte foi por causa que a minha família não aceitou se declarar como índio. Então eles se achavam como índios e os direitos só eram pra eles e não eram pra nós. Nós como extrativistas associados à Associação do Auati-Paraná, eles resolveram sair do quadro de sócios pra ser índio. Quer dizer eles tem mais direito do que nós e só vamos ter direito se a gente se declarar como índio, senão a gente ia ser excluído. Mas não, a gente também tinha direito, sendo índio ou não sendo a gente também tinha direito. Até que a terra fosse demarcada a gente garantia o direito também. Aí começou a briga. Chegou até a ter quase morte entre famílias, foi uma coisa muito séria. E só não teve briga porque na época eu era coordenador e eu fui em cima pra evitar. (Presidente da AAPA e comunitário de Itaboca)
}

Ao contrário dos argumentos dos comunitários de Itaboca, o líder do movimento indígena acredita que o ato de assumir a identidade Cocama é um importante passo para o início de um processo de insubordinação. Esta questão não está reduzida apenas a uma competição por recursos escassos, mas estes grupos devem ser observados considerando sua relação com outros grupos nas diversas esferas do contexto do Estado.

Em seu trabalho de mobilização, o líder indígena de Tefé organizou diversas reuniões na comunidade Itaboca a fim de convencer seus parentes a optarem pela identificação indígena. Os Cocama consideram-se responsáveis e verdadeiros donos da área e graças aos 
atritos prévios não querem autorizar os comunitários de Itaboca a explorar os lagos. Vários acordos foram firmados e resultaram em uma autorização provisória, sempre mediados pelos funcionários do CEUC, IBAMA e ICMBio, contudo assim que conseguirem homologação da Terra Indígena, os Cocama afirmam que será vetado o acesso dos comunitários ao complexo do Buiuçu.

Os comunitários alegam que o bloqueio prejudicará muito as famílias, já que Itaboca está situada em uma área de várzea, na qual os constantes alagamentos das roças inviabilizam a produção familiar mesmo em pequena escala. Isto os torna mais dependentes do complexo. A pergunta que se destaca nestes relatos é: quem vai se beneficiar mais, o indígena ou o extrativista?

De acordo com o líder indígena, Itaboca e Santa União:

Se dividiram por intermédio dessa vontade de criação de terra indígena. O pessoal do Itaboca não se identificaram e eu com muito cuidado ia lá e dizia: eu conheço vocês, eu sei que vocês são indígenas. Olha, terra indígena indígena não é moeda de negócio. É uma terra que se recebe pra gente preservar. A terra é do governo federal e é vocês que vão ser os vigias da terra.

Aí eu fiz três reunião lá na Santa União. Mas da última vez foi em Fonte Boa e eles: mais uma vez nós fica de fora. Então tá bom. Aqui meu tem sobrinho, tem sobrinho da minha mulher, tem tio, tem tia. Vocês não querem então tá bom. Tudo bem. Agora vocês vão sofrer uma separação que é crucial para vocês. Porque vocês moram ali, vocês dependem daquela área ali, porque onde vocês moram não tem nenhum lago. Isso eu falei pro presidente muitas vezes. Eu disse: olha, vocês não tem lago, como é que vocês pensam em se sustentar? É, mas desse lado da reserva tem mais de 400 lagos. É, mas onde é que fica? Então foi isso que aconteceu.

Esse racha, através do benefício que o pessoal da Santa União enxergaram e o Itaboca não chegou a entender. Eu acho que não chegaram a entender. Aí ficou nesse impasse. Até a terra ser demarcada e aí acaba a briga. Todo ano tem que fazer acordo. Todo ano tem conflito. Já chegou de acontecer do pessoal da Itaboca espancar o pessoal da Santa União, alagar as canoas, chegou a esse ponto. Por isso que me chamaram pra tentar contornar. Não resolveu, mas contornou um pouco. E daqui e acolá o Itaboca quer entrar direto, quer levar pesqueiro até no mês de abril. O Itaboca querendo levar peixeiro e o Itaboca foi barrado.

Ao declarar-se indígena, o grupo automaticamente declara a diferença. Essa aparente 
diferença cultural perturba o ideal de unidade de conservação que, tal como mostrou Bhabha (1998) sobre a ideia de nação, é pensado como homogênea. O étnico aqui também precisou ser deslocado, literalmente, para o município de Jutaí em busca da conversão para uma religião que pudesse salvá-los da condição social em que viviam. A liminaridade de um povo, segundo este autor, exige um objeto pedagógico e um sujeito performativo, e as estratégias discursivas e performáticas dos Cocama não coincidem com um comportamento esperado por aqueles que determinam a legitimidade e o direito de permanência no lugar, ou seja, o Estado e suas diversas instâncias.

No entanto há um outro discurso que aparece nessa disputa pelo território:

\footnotetext{
O nosso tio era apenas o chefe da UNITEFÉ, e como chefe da UNITEFÉ ele orienta qualquer grupo que tá assim, que se forma indígena como Santa União, assim como levar. Ele é pra apoiar. Agora, só que ele apoiou assim de uma forma, ele queria mesmo era tocar a Itaboca, que tirasse de fora naquela hora e acabou-se. Porque Itaboca é branco e acabou-se, Santa União tinha direito e Itaboca não. Depois de várias reuniões ele encarava a gente mesmo. Ele considerou a gente como extrativista e não tinha o direito nem de falar, porque a Lei deles era maior do que a nossa, a Funai tinha mais poder do que a gente. A briga era contra o extrativista, extrativista é isso, é aquilo. A Funai tem poder e é a Lei maior, assim que ele fala, é a lei maior. A Funai é a lei maior e acabou-se. (Presidente da AAPA)
}

Portanto, "Quem possui mais poderes? A Funai, vinculada ao Ministério da Justiça ou o ICMBio, vinculado ao Ministério do Meio Ambiente?" As tensões institucionais também são um destaque nesta querela. Os indígenas no âmbito da RDS Mamirauá são reconhecidos como usuários. Apesar de os administradores da área considerarem diversos acordos de cooperação técnica com outras instituições, como a Funai, os dados concretos mostram que essas cooperações estão apenas no plano abstrato ou documental.

\section{Política Ambiental brasileira: a reserva e o projeto sustentável como produtores de homogeneização da Amazônia}

Seja qual for a categoria de unidade de conservação é necessário compreender sua criação e implementação no contexto do tempo e do lugar que ocorre, que trata-se de uma 
questão política, social e econômica. A formação do Estado-Nação brasileiro passou por uma mudança de atitude com relação ao seu maior bem: os recursos naturais. O papel conservacionista brasileiro já dava sinais desde 1658, onde já se falava em proteção de florestas e mananciais. Portanto o interesse em conservar é mais antigo que a experiência norte-americana e veio a se destacar durante a ditadura militar, devido às pressões globais e locais.

Ao situar histórica e sociologicamente a conformação das Unidades de Conservação de Proteção Integral como um instrumento de política ambiental, Barreto Filho (2001) mostra ainda que havia uma necessidade histórica de uma codificação e disciplinarização dos recursos naturais para fortalecer e promover o progresso do país. $\mathrm{O}$ empenho na criação de unidades de conservação, afirma o autor, objetivou a ordenação territorial para uma regulação e apropriação do uso dos recursos naturais como propriedade do Estado.

Com a grande pressão de diversos setores da sociedade (como organizações nãogovernamentais e os movimentos sociais), o governo brasileiro respondeu com uma política ambiental "de caráter nacionalista e o afunilamento de seus canais de interlocução face às demandas daqueles movimentos, concentrando a autoridade num único centro de poder, visando disciplinar e centralizar as decisões relativas à Amazônia” (BARRETO FILHO, 2006, 132). Contudo, as estratégias desenvolvidas pelos principais interessados, os seringueiros, mobilizando órgãos internacionais levou à criação da primeira Reservas Extrativista brasileira, a Resex do Alto Juruá (Acre).

A partir da década de 1920, e principalmente de 1930, houve grande produção legislativa com o intuito de gerir os recursos naturais. Esse processo se intensificou a partir do final da década de 1970, e o que parecia um paradoxo no governo da ditadura militar - o caráter liberal-desenvolvimentista ao mesmo tempo em que instaurava um planejamento conservacionista rígido e autoritário da Amazônia - tratava-se de uma ação conjunta que fortificou o ideal da conservação por meio do domínio técnico-burocrático das reservas, contribuindo para o projeto desenvolvimentista da ditadura.

A política ambiental militar brasileira inicialmente se caracterizou por incentivo à ocupação demográfica e de desenvolvimento econômico da Amazônia, trata-se da chamada política de integração nacional, que já vinha sendo elaborada desde os anos 50, com a criação 
da Superintendência do Plano de Valorização Econômica da Amazônia (ADOLPHO, 1951) ${ }^{12}$. Esta política se estabeleceu em vários planos regionais, como a Operação Amazônia, o Plano de Integração Nacional, o Programa Polos Agropecuários e Agrominerais da Amazônia, com o objetivo de desenvolver a infra-estrutura, incentivos a créditos fiscais, créditos subsidiados para atrair as empresas que pudessem desempenhar esse papel empreendedor, permitindo a colonização pública e implementar grandes projetos agropastoris (KOHLHEPP, 2002).

Apesar dessa política desenvolvimentista, o governo militar também demonstrou interesse numa política conservacionista. A “Operação Amazônia” abarcava não apenas uma política de proteção das fronteiras contra o inimigo externo e a cobiça internacional, que coincidia com as frágeis fronteiras amazônicas, mas num conjunto de estratégias cuja preocupação principal era a superação do atraso.

A partir de 1979 ocorreu um grande impulso para a criação de novas unidades de conservação de proteção integral - como estação ecológica, reserva biológica, parque nacional, monumento natural e refúgio da vida silvestre - particularmente na Amazônia. As medidas conservacionistas coincidiram com a frente de expansão agrícola na região, e base dessa "política conservadora", por meio do domínio científico-tecnológico, trata-se controle autoritário e racional do Estado. Controle este que acompanhou os diversos planos nacionais de desenvolvimento da região, que ocorreu no âmbito das atividades econômicas, no plano político, social e de defesa do país (principalmente das fronteiras), com a justificativa de que resultaria no progresso e desenvolvimento do país, mas sempre pautado na economia de mercado.

Como uma tentativa de contrariar essas políticas governamentais, diversos grupos politizados começaram a aparecer num cenário que chamava atenção apenas à degradação ambiental, fruto de uma política conservacionista que negava a existência de pessoas nesse locais mais afetados. Foi neste contexto de reivindicação e luta pelos direitos à terra e ao uso dos recursos naturais que as Reservas Extrativistas foram criadas e implementadas.

Esta modalidade de unidade de conservação não surge de maneira isolada, mas é fruto

\footnotetext{
12 O Plano de Valorização Econômica da Amazônia, proposto pelo senador Álvaro Adolpho, que instituiu em janeiro de 1953 a Superintendência do Plano de Valorização Econômica da Amazônia (SPVEA). Essa iniciativa foi possível a partir da base o cenário do pós-guerra, no qual a intervenção do Estado Nacional na economia ganhou força, junto com os pressupostos de da eficácia do planejamento do desenvolvimento regional. Tais ideias influenciaram as estratégias para uma modernização da Amazônia a partir da intervenção estatal, e que contribuíram para a implementação deste programa de desenvolvimento financiado por uma parcela de $3 \%$ de impostos federais durante vinte anos (MONTEIRO \& COELHO, 2004).
} 
da reivindicação de "unidades de mobilização" (ALMEIDA, 1994), ou seja, forças sociais que, embora heterogêneas, produzem alterações nos "padrões tradicionais de relações política com os centro de poder e com instancias de intermediação, possibilitando a emergência de lideranças que prescindem dos que detém o poder local" (p. 523). Constituindo-se com uma reação às políticas governamentais, cujo objetivo era somente a estimulação à produção agrícola e a chamada "fixação do homem à terra", como uma reprodução de políticas governamentais.

No contexto do Auati-Paraná pergunta-se: como um projeto que inicialmente se configurava pelo empenho para a modificação da condição social das pessoas foi se transformando a ponto de se estabelecer um conjunto de modos de regulação social burocratizado? A partir de então, "onde há conflito, não há manejo" - o lema das instituições gestoras - constitui-se como uma das maneiras de se estabelecer um processo civilizador: o uso racional dos recursos naturais. Civilizar significa reorganizar os relacionamentos humanos, uma maneira de tentar pacificar essa "natureza" individualista e pouco gregária em nome da existência grupal e harmônica.

Uma forma de controle desse processo é a classificar e documentar a ação das populações. Um exercício observado no Plano de Gestão da RDS Mamirauá foi a elaboração de um quadro classificatório dos grupos indígenas localizados nos limites da reserva como: índios usuários, que ocupam áreas do entorno da reserva; índios das áreas sobrepostas, que tiveram suas terras demarcadas antes da criação da reserva; e comunidades ribeirinhas com solicitação de pedidos de reconhecimento da identidade indígena junto à FUNAI.

\begin{tabular}{|l|l|}
\hline \multicolumn{1}{|c|}{$\begin{array}{c}\text { CATEGORIAS DE } \\
\text { INDÍGENAS }\end{array}$} & \multicolumn{1}{c|}{ DESCRIÇÃO } \\
\hline Os índios usuários & $\begin{array}{l}\text { São os Miranha da Terra Indígena Cuiu-cuiu e os Ticuna da } \\
\text { Terra Indígena Tupã Supé, suas terras estão situadas no } \\
\text { entorno da RDS, na margem esquerda do Rio Japurá e na } \\
\text { margem direita do Rio Solimões, respectivamente. Foram } \\
\text { reconhecidos como usuários e lhes atribuído o direito a usar } \\
\text { os recursos naturais da Reserva Mamirauá, mas de acordo } \\
\text { com as normas do Plano de Manejo da reserva e nas áreas }\end{array}$ \\
\hline
\end{tabular}




\begin{tabular}{|l|l|}
\hline $\begin{array}{l}\text { Os índios das áreas } \\
\text { sobrepostas à RDS }\end{array}$ & $\begin{array}{l}\text { São os Cambeba da Terra Indígena Jaquiri, que tiveram seu } \\
\text { processo de demarcação de território anterior à criação da } \\
\text { reserva; os Tikuna da Terra Indígena Porto Praia, cujo } \\
\text { processo de demarcação territorial foi posterior à criação da } \\
\text { reserva. Neste grupo tem ainda os Cocama da Terra Indígena } \\
\text { Acapuri de Cima e os Tikuna da Terra Indígena Uati-Paraná. }\end{array}$ \\
\hline $\begin{array}{l}\text { Comunidades ribeirinhas com } \\
\text { solicitação de pedidos de } \\
\text { reconhecimento da identidade } \\
\text { indígena junto à FUNAI }\end{array}$ & $\begin{array}{l}\text { Neste grupo tem usuários e moradores. A partir de 2004, } \\
\text { várias comunidades de moradores e/ou de usuários da } \\
\text { de reconhecimento de suas etnias indígenas, e respectivos } \\
\text { territórios, para a Fundação Nacional do Índio. }\end{array}$ \\
\hline
\end{tabular}

Quadro 1: Classificação étnica dos indígenas presentes na RDS Mamirauá. Fonte: IDSM, 2010, adaptado.

Os índios não são classificados por suas habilidades, mas por sua relação conflituosa com a unidade de conservação, ou seja, o grau de integração ao Plano de Gestão da unidade. A presença indígena preocupa os gestores da unidade, principalmente pelo não cumprimento das normas e regras estabelecidas pelo Plano de Gestão e o comprometimento com outros padrões de convivência. Justamente, os conflitos evidentes podem promover uma imagem negativa da unidade.

Segundo o Plano de Gestão, "é profundamente relevante para a conservação da biodiversidade, a forma pela qual estes acessos se darão por estas comunidades que se encontram em processo de reconhecimento da identidade étnica e reivindicação territorial" (IDSM, 2010, p. 183). Além disso, se essas novas solicitações de terras indígenas forem realmente efetivadas teriam que se adaptar às normas e regras específicas da RDS Mamirauá.

Os efeitos sociais de presença indígena preocupa os gestores principalmente pelo não cumprimento das normas e regras estabelecidas pela RDS Mamirauá e o comprometimento com outros padrões de convivência. Além disso, os conflitos evidentes podem promover uma 
imagem negativa da unidade de conservação, algo que os gestores parecem se esforçar em omitir. A identidade indígena causa tensão: ela coloca em risco o processo de regulamentação estatal. A classificação dos grupos indígenas em função da localização e da adesão ao Plano de Gestão indica a preocupação com as definições dos limites internos e externos. O ideal seria uma reserva habitada por pessoas que seguissem o modelo de comportamento viável para a administração local.

Os possíveis conflitos que surgem a partir dessa nova modalidade de uso social, implica resoluções forçada ou por omissões. A coação externa, internalizada, passa a regular internamente os impulsos dos comportamentos das pessoas envolvidas. O modelo comunitário do desenvolvimento sustentável, presente nos discursos institucionais, prevalece nas decisões das instâncias administrativo-financeiras. Um projeto de proporções internacionais (que recebe financiamentos de diversas instituições nacionais e internacionais) provoca discussões sobre as formas de se institucionalizar papeis sociais na busca do “desenvolvimento sustentável”. Trata-se da implementação de um cenário estatisticamente viável, no qual um dos princípios básicos é regular o modo ser, de se relacionar com a natureza e com o outro.

\section{Algumas considerações finais}

A categoria unidade de conservação de uso sustentável admite a presença de pessoas, entretanto não pode ser qualquer pessoa. Elas devem ter como atributo oficial ações para compatibilizar a conservação da natureza com o uso sustentável, ou racional, dos recursos naturais. Mas os limites desse atributo ultrapassam o código legal, pois percebe-se que o modelo de desenvolvimento característico das unidades de conservação de uso sustentável preconiza o ideal comunitário cristão de convivência.

Nesse ideal os seres humanos devem viver em harmonia e sempre sob a tutela externa de especialistas ambientais para legitimar as intervenções políticas e administrativas. Ou seja, os mediadores sociais são extremamente necessários para a relação estabelecida. É neste sentido que no jogo de dominação, o código jurídico é complementado pelo código moral cristão na regulação do comportamento da população local, sejam indígenas, extrativistas ou qualquer outra categoria política que demonstre ameaça à gestão e até mesmo à proteção dos recursos naturais. 
As três palavras-chave do título - conscientização, tradição e desenvolvimento - estão presentes no processo de institucionalização das políticas ambientais, disseminado a partir de programas de setores estatais e não-governamentais. Elas enunciam um conjunto de normas e regras para a ação coletiva e é neste cenário que emergem grupos indígenas, não apenas como grupos politizados competindo por recursos, mas trazendo a discussão questões como a diferença e a autenticidade na produção de identidade.

A compreensão dessa dimensão da organização territorial, a partir da implementação das unidades de conservação, exige não somente o mapeamento das características do ambiente físico, mas a apreensão dos conceitos específicos nas relações entre os agentes sociais, os dispositivos institucionais e os diversos elementos que tornaram possível essa construção. Portanto, é necessário compreender a atuação concreta dos atores neste campo de disputas e as diversas concepções sobre o espaço e seu ordenamento, tais como as definições legais e jurídicas, técnico-científicas, os saberes tradicionais, a atuação dos diversos segmentos como movimentos sociais, instituições conservacionistas, religiosas e administrativas. 


\section{Referências Bibliográficas}

ADOLPHO, Álvaro. Plano de Valorização Econômica da Amazônia. Rio de Janeiro: Departamento de Imprensa Nacional, 1951.

ALMEIDA, Alfredo W. B. "Universalização e localismo: movimentos sociais e crise dos padrões tradicionais de relação política na Amazônia”. In: D'INCAO, M. A; SILVEIRA, I. M. (Orgs.). A Amazônia e a crise da modernização. Belém: Museu Paraense Emílio Goeldi, 1994.

AMARAL, E. S. R. “A comunidade e o mercado: os desafios na comercialização de pirarucu manejado das reservas Mamirauá e Anamã, Amazonas - Brasil”. In: Uakari, v. 3, n. 2, 7-17, dezembro 2007.

ARANTES, Miguel. Histórico da Resex Auati-Paraná. Relatório Técnico. Fonte Boa, 2006.

BANTON, M. A ideia de raça. Lisboa: edições 70, 1977.

BARRETO FILHO, Henyo T. Da nação ao planeta através da natureza: uma abordagem antropológica das unidades de conservação de proteção integral na Amazônia Brasileira. Tese de Doutorado. São Paul: USP, 2001.

BHABHA, H. K. "DissemiNação: o tempo, a narrativa e a as margens da nação moderna". In: , H. K. O local da cultura. Belo Horizonte: Ed. UFMG, 1998.

CARSOSO DE OLIVEIRA, R. "Possibilidade de uma antropologia da ação entre os Tükúna". Série Antropologia Social: 11. Brasília: Fundação Universidade de Brasília, 1975.

DURKHEIM, Emile. Leçons de sociologie. 3. ed. Paris: Quadrige/PUF, 1997. 
EPSTEIN, A. L. Ethos and Identity: three studies in ethnicity. London: Tavistock Publications; Chicago: Aldine Publishing Company, 1978.

ERTHAL, R. M. de C. O suicídio Ticuna na região do Alto Solimões - AM. Tese (Doutorado em Saúde Pública) - Escola Nacional de Saúde Pública, Fundação Oswaldo Cruz, 1998. Disponível em: http://portalteses.icict.fiocruz.br/pdf/FIOCRUZ/1998/erthalrmcd/capa.pdf .

IDSM. Plano de Gestão Reserva de Desenvolvimento Sustentável Mamirauá - RDSM. Vol 1. Diagnóstico. Tefé, 2010.

KOHLHEPP, G. "Conflitos e interesses no ordenamento territorial da Amazônia Brasileira". Estudos Avançados, 16 (45), 2002.

MAUSS, Marcel. “La nation”. In: MAUSS, Marcel. Oeuvres. v. 3. Paris: Minuit, 1969.

MONTEIRO, M. A ; COELHO, M. C. N. "As políticas federais e reconfigurações espaciais na Amazônia”. Novos Cadernos - NEAE, vol. 7, n. 1, p. 91-122, jun 2004.

PIRES MENEZES, M.L. “Trabalho e Território: as missões católicas no interior do estado do Amazonas, Brasil”. Scripta Nova, Revista Electrónica de Geografía y Ciencias Sociales, Universidad de Barcelona, vol. VI, $\mathrm{n}^{\mathrm{o}} 119$ (11), 2002. [ISSN: 1138-9788] http://www.ub.es/geocrit/sn/sn119-11.htm.

TASTEVIN, Constant. "A região do Solimões ou o Médio-Amazonas (Amazonas, Brasil)". In: FAULHABER, P.; MONSERRAT, R. (org). Tastevin e a etnologia indígena: coletânea de textos traduzidos em Tefé (AM). Rio de Janeiro: Museu do Índio, 2008.

WEBER, Max. Economia y Sociedad. Mexico: Fondo de Cultura Económica, 1983. 